\title{
Antecedents of Post-adoption Expectations: A Study in the e-Learning Context
}

\author{
A.K.M. Najmul Islam \\ Turku Center for Computer Science (TUCS), University of Turku, Finland \\ najmul.islamatse.fi
}

\begin{abstract}
This paper examines factors influencing post-adoption expectations toward an e-learning system. Following the expectation-confirmation based information system continuance theory, we use perceived usefulness as the surrogate of post-adoption expectations. Then, we propose a research model based on the prior literature where we hypothesize a number of factors along with the confirmation of initial expectations affect perceived usefulness. The model is tested among the university educators $(n=175)$ who use an e-learning system to conduct their teaching. The results suggest that post-adoption expectation is driven by confirmation of initial expectations, perceived control beliefs, and perceived system quality. Subjective norm does not have significant impact on post-adoption expectations. The determinants of perceived usefulness explained $68 \%$ of its total variance.
\end{abstract}

Keywords: Expectation-confirmation theory, e-learning, Perceived usefulness, Post-adoption expectations.

\section{Introduction}

During the recent years, e-learning via the Internet has become so common phenomenon that it has boosted the use of software tools that lent structure and management for online courses. These tools are called Course Management Systems (CMS) which feature educators with easy communication to the students, the ability to track students' progress, and a mean to presenting content for online courses securely. Such e-learning tools are very attractive to the universities because they have many useful features. However, while evaluating an e-learning system like a CMS, educators' perspective must be considered. The success of such technology depends on the educators' willingness of its continued utilization. It is argued in the literature that continued utilization is determined by post-adoption expectation and satisfaction [1].

Despite its importance in explaining continued use, a little effort has been given to identify factors that shape post-adoption expectations. However, it is very important for practitioners to know what shapes post-adoption expectations to plan for interventions that could influence post-adoption satisfaction and continued use. It is even more important for the e-learning service providers as the courses utilizing elearning platforms are still evolving. 
Prior research studies have assumed perceived usefulness as the surrogate measure of post-adoption expectations [1]. Perceived usefulness is defined as the degree to which a user believes that using a particular system would enhance his or her job performance [2]. Researchers have found a number of antecedents of perceived usefulness in IS adoption studies such as perceived ease of use, subjective norm, image, job-relevance etc [3]. However, most of these studies do not differentiate between pre-adoption and post-adoption stage. Indeed, some factors have been shown to predict perceived usefulness during post-adoption stage. For example, perceived ease of use has been often found as a significant determinant of perceived usefulness during post-adoption IS use [4]. Given that the psychological motivation behind initial adoption and subsequent use being different [1], further research is necessary to underpin the important factors that shape perceived usefulness during post-adoption stage.

Thus, this paper addresses the following research question: what are the antecedents of post-adoption expectations toward an e-learning system? In answering this question, we draw different factors from the IS adoption and post-adoption literature and use expectation-confirmation based IS continuance theory [1] as the foundation theory to build our research model. Then, we test our proposed research model by collecting survey data among university educators who use a popular elearning platform, Moodle (http://moodle.org/) to conduct their teaching.

The paper proceeds as follows. In section 2, we present the theoretical background. In section 3 we develop our research model. Section 4 is dedicated to the research method and section 5 presents the data analysis results and discussion. In section 6 we describe implications of our findings for theory and practice. Finally, section 7 concludes the paper.

\section{Theoretical Background}

The root of post-adoption expectations is the expectation-confirmation theory [5]. This theory hypothesizes that consumers' level of satisfaction with a product/service determines repurchase intention. In turn, consumer satisfaction is determined by two major constructs: initial expectations (pre-purchase expectations) on a product/ service, and discrepancies between expectations and product/service performance (disconfirmation). According to this theory, buyers first develop expectations about a product/service before purchase. Second, their consumption experiences with it build perceptions about its performance. This leads to the buyer either confirming or disconfirming the pre-purchase expectations, after assessing perceived performance against the earlier frame of reference (pre-purchase expectations). A buyer's expectations are confirmed when the product/service performs as much as expected; negatively disconfirmed when it performs worse than expected; positively disconfirmed when it performs better than expected [5].

Drawing attention to the substantial difference between initial adoption and continued usage, the information system continuance model was developed from the expectation-confirmation theory and empirically tested in voluntary environment [1]. 
The information system continuance model focuses importance on post-adoption expectations rather than pre-adoption expectations. According to the model, perceived usefulness is the measure of post-adoption expectations, since among the cognitive beliefs in IS adoption and usage, perceived usefulness demonstrated itself to be the most consistent and salient one in determining the user intention over time [1]. The information system continuance model posits that the users after first time acceptance and a period of initial use will form an opinion to which their pre-acceptance expectations are confirmed (Confirmation). From this confirmation, the users form an opinion about the benefits (Perceived usefulness). After a period of time, both confirmation and perceived usefulness are the basis of satisfaction with the IS (Satisfaction). Finally, perceived usefulness and satisfaction impact the users' willingness to continue the IS (intention). The information system continuance model is shown in Fig. 1.

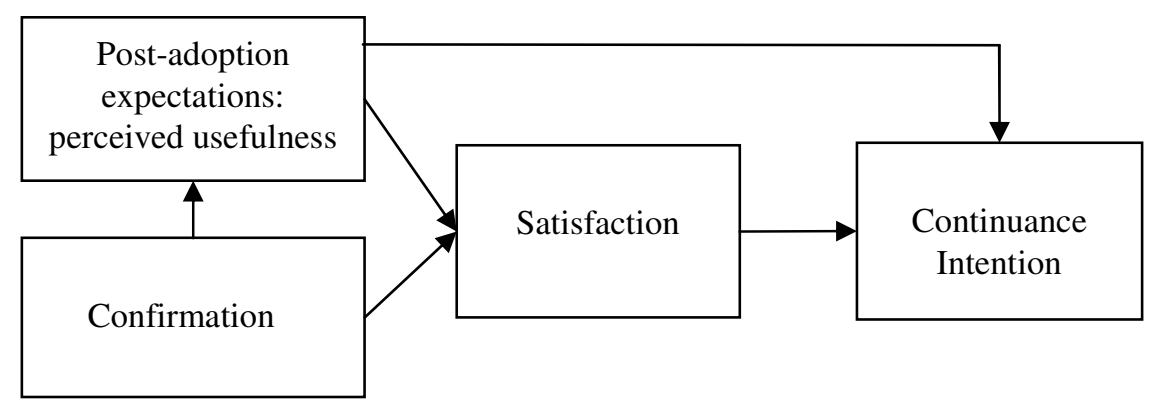

Fig. 1. IS continuance model [1]

\section{Research Model}

Utilizing the expectation-confirmation based IS continuance theory and other complementary theories, prior studies have found a number of antecedents in addition to confirmation that shape perceived usefulness in different contexts including elearning system utilization. These antecedents fall into three broad categories: system quality related factors, individual's control beliefs, and social aspects related factors. Perceived ease of use [4], perceived playfulness [6], and perceived task-technology fit/perceived compatibility [7] may fall into system quality category. A few studies used perceived competency that falls into individual's control belief category [6;8]. Under social aspects category, the researchers tested the effect of subjective norm on perceived usefulness [9]. In this study, to determine post-adoption expectations, we use these three categorical factors in addition to the confirmation of initial expectations. Fig. 2 shows the research model. In the following, we describe these factors and build our hypotheses.

Confirmation is a cognitive belief which is defined as the extent to which users' expectations of e-learning system use is realized during actual use [1]. The expectation-confirmation based IS continuance theory posit that confirmation of 
expectations has an effect on perceived usefulness. Many studies have found a significant effect of confirmation on perceived usefulness in different contexts including e-learning system $[4 ; 6]$. Thus, we make the following hypothesis.

H1. Educators' confirmation of expectations of an e-learning system positively affects their perceived usefulness with the e-learning system.

Control beliefs are related to an individual's beliefs about the presence of factors that may facilitate or impede performance of the e-learning system use [10]. We argue such control beliefs would lead educators to realize the usefulness of an e-learning system. After using an e-learning system, the educators develop cognitions about the control beliefs that may facilitate or impede performance of the e-learning system use. Educators' cognitions about such beliefs would lead them to understand the e-learning system's capabilities and develop appropriate level of post-adoption expectations during the post-adoption stage. Thus, we propose the following hypothesis.

H2. Educators' perceived control beliefs with an e-learning system positively affect their perceived usefulness with the e-learning system.

Based on the prior studies in the IS continuance, we operationalize control beliefs as a second-order construct having two reflective constructs: perceived behavioral control and perceived competency. Perceived behavioral control refers to people's perception of the ease or difficulty of performing the behavior of interest [10]. Perceived competence refers to being effective in dealing with the e-learning system a user works with [11]. It is one of the three psychological needs those are the basis of self-determination theory [12].

System quality is a general perception about a system in terms of its performance and it can be reflected by various system features. We argue that experience with using the e-learning system to conduct various tasks can produce a better understanding of its characteristics, which can assist the user in forming cognitions about its overall usefulness. We argue that if the users of a system develop cognitions about its perceived system quality, it would, in turn, affect their cognitions about its perceived usefulness. Seddon [13] proposed an association between system quality and perceived usefulness in his modified IS success model. Latter, Lee and Lee [14] found a significant causal relationship between e-learning environment quality and perceived usefulness. Thus, we make the following hypothesis.

H3. Educators' perceived system quality of an e-learning system positively affects their perceived usefulness with the e-learning system.

System quality has been operationalized in many different ways in IS literature. In general, the manifest variables of system quality in terms of a web-based system are access convenience, flexibility, integration, response time, sophistication, reliability, accessibility, stability, system speed, usability, ease of use, navigation and network speed [15]. Among these variables compatibility, ease of use, access, and reliability are the most important system quality related variables during post-adoption stage [15]. Thus, we model system quality as a multi-dimensional construct composed of four reflective constructs: perceived compatibility, perceived ease of use, perceived access, and perceived reliability in this paper. Perceived compatibility is defined as the degree to which an e-learning system is perceived as being consistent with 
existing values, needs and experiences of the users [16]. Perceived ease of use is defined as the degree to which a person believes that using a system would be free of effort [2]. Perceived access refers to the degree of accessibility, responsiveness, stability, and availability of the e-learning system [15]. Perceived reliability refers to the dependability of the e-learning system operation [17].

Social norm refers to the person's perception that most people who are important to him think he should or should not perform the behavior in question [18]. Social norm has been shown to have a direct impact on behavioral intention in literature [3]. It has also been theorized to have an indirect effect on behavioral intention through perceived usefulness [19]. It implies that when one perceives that an important referent thinks one should use a system, one incorporates the referent's belief into one's own belief structures [19]. Thus, we hypothesize the following.

H4. Social norm positively affects their perceived usefulness with the e-learning system.

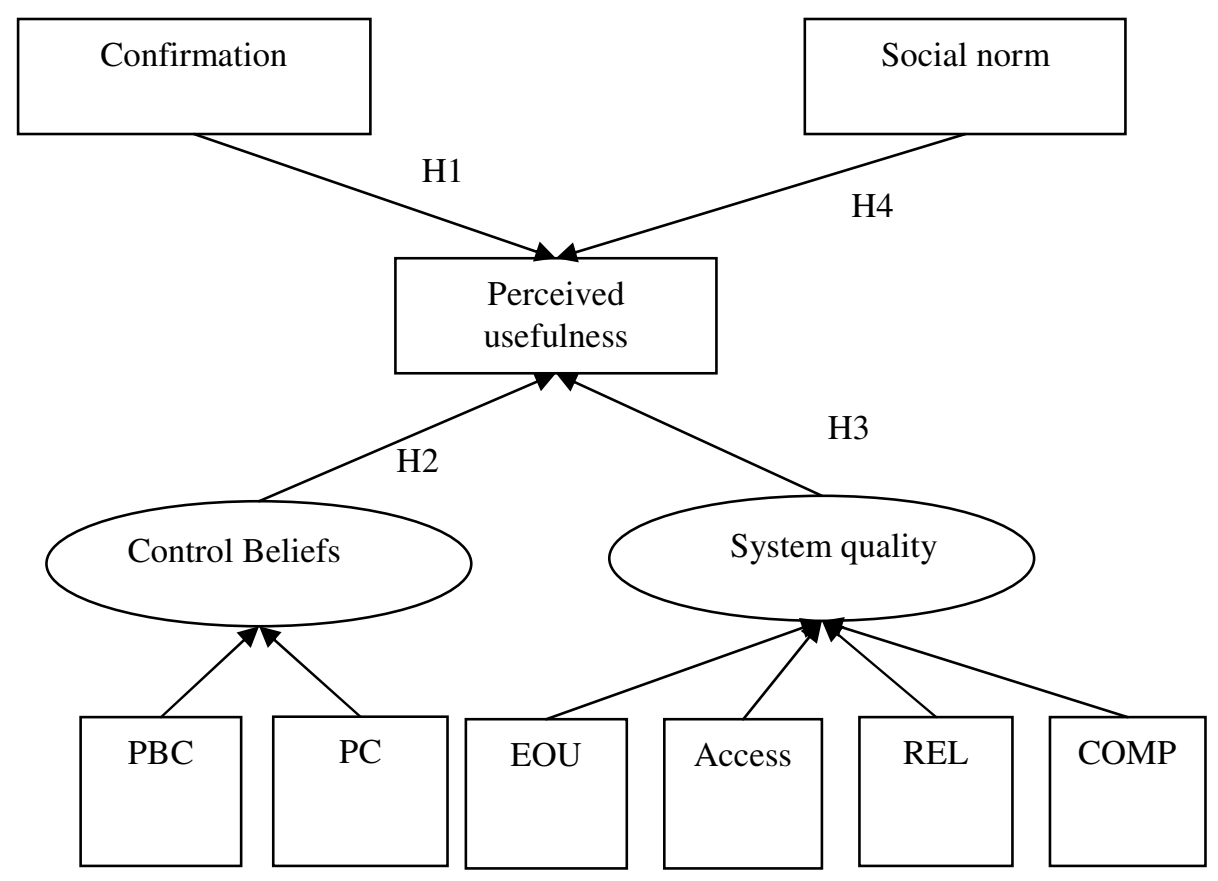

Fig. 2. Research model

\section{Research Method}

\subsection{Questionnaire Development}

Each item corresponding to the constructs has been measured using the seven-point Likert scale, with answer choices ranging from "Strongly disagree (1)" to "Strongly 
agree (7)". Most of these items are adapted from the literature with minor changes in wording reflecting the target technology. The measures of confirmation and perceived usefulness were adapted from Bhattacherjee [1] while the measures of perceived ease of use were adapted from Davis [2]. The measures of perceived compatibility and subjective norm were adapted from Moore and Benbasat [16] and Venkatesh et al. [20] respectively. Finally, the measures of perceived competence were adapted from Sorebo et al. [8]. After the questionnaire was drafted, it was first sent to two academic researchers for their review and revised according to their comments and suggestions to make the wording of the items more precise. Then, the questionnaire was sent to 30 educators at the university, so that they could review it. Overall, the educators indicated that the questionnaire was relatively clear and easy to complete. A number of suggestions were made concerning the wording of several items and the overall structure of the questionnaire. The questionnaire was revised according to the given suggestions.

\subsection{Data Collection}

Data was collected via a web-based survey from the educators of a university in Finland who use Moodle for their teaching purpose. A list of educators' email addresses was collected from the Moodle support team in the university. A total of 1012 email invitations were sent to the educators of the university who had been the registered Moodle users. Two reminders were sent to increase the response rate in two weeks gaps. The survey ran for approximately one and half months. After filtering invalid and incomplete responses, we had total 207 survey responses. In this particular study, we were interested about those users who had been conducting at least one course using Moodle at that academic year. After filtering the survey responses according to this criterion, we ended up with 175 usable responses. The demographic information of the respondents is given in Table 1.

Table 1. Demographic information

\begin{tabular}{llll}
\hline & & Frequency & Percent \\
\hline Gender & Male & 74 & 42.3 \\
& Female & 101 & 57.7 \\
Age & 21-40 years & 90 & 51.4 \\
& $>41$ years & 85 & 48.6 \\
Experience with the target & $0-18$ months & 54 & 30.9 \\
technology & $>18-36$ months & 83 & 47.4 \\
& $>36$ months & 38 & 21.7 \\
\hline
\end{tabular}

\subsection{Data Analysis}

We employed partial least squares (PLS) as our analysis approach and utilized the tool smartPLS [21]. PLS is a second generation regression method that combines 
confirmatory factor analysis with linear regression, and this makes it possible to run the measurement and structural models simultaneously.

Table 2 shows item wise averages and loadings of each construct in the model. For each construct the assessment of convergent validity or internal consistency is also included through the composite reliability coefficient [22]. Convergent validity indicates the extent to which the items of a scale that are theoretically related are also related in reality. As we can see from Table 2, all items have significant path loadings greater than threshold 0.7 recommended by Fornell and Larcker [22]. All the constructs have composite reliability values that exceed the threshold recommended by Nunnally [23].

Table 2. Construct items, means and internal consistencies

\begin{tabular}{|c|c|c|c|c|}
\hline Construct & Item & Mean & std & Loading \\
\hline \multirow{5}{*}{$\begin{array}{l}\text { Perceived } \\
\text { usefulness (CR } \\
=0.92)\end{array}$} & $\begin{array}{l}\text { PU-1: Using Moodle increases the control } \\
\text { with my teaching plan }\end{array}$ & 4.59 & 1.33 & $0.84 *$ \\
\hline & $\begin{array}{l}\text { PU-2: Using Moodle enables me to } \\
\text { accomplish teaching information sharing } \\
\text { more quickly }\end{array}$ & 5.8 & 1.33 & $0.78^{*}$ \\
\hline & PU-3: Using Moodle is of benefit to me & 5.18 & 1.28 & $0.85^{*}$ \\
\hline & $\begin{array}{l}\text { PU-4: The advantages of Moodle outweigh } \\
\text { the disadvantages }\end{array}$ & 5.31 & 1.23 & $0.87 *$ \\
\hline & $\begin{array}{l}\text { PU-5: Overall, using Moodle is } \\
\text { advantageous }\end{array}$ & 5.65 & 1.22 & $0.80 *$ \\
\hline \multirow[t]{4}{*}{$\begin{array}{l}\text { Ease of use } \\
(\mathrm{CR}=0.93)\end{array}$} & $\begin{array}{l}\text { PEOU-1: My interaction with Moodle is } \\
\text { clear and understandable }\end{array}$ & 4.46 & 1.52 & $0.88 *$ \\
\hline & $\begin{array}{l}\text { PEOU-2: Interacting with Moodle does not } \\
\text { require a lot of mental effort }\end{array}$ & 4.38 & 1.52 & $0.75^{*}$ \\
\hline & PEOU-3: I find Moodle to be easy to use & 4.49 & 1.52 & $0.94 *$ \\
\hline & $\begin{array}{l}\text { PEOU-4: I find it easy to get Moodle to do } \\
\text { what I want to do }\end{array}$ & 4.27 & 1.61 & $0.91 *$ \\
\hline \multirow{3}{*}{$\begin{array}{l}\text { Perceived } \\
\text { Compatibility } \\
(\mathrm{CR}=0.91)\end{array}$} & $\begin{array}{l}\text { COMP-1: Using Moodle fits with the way I } \\
\text { like to teach }\end{array}$ & 4.95 & 1.40 & $0.92 *$ \\
\hline & $\begin{array}{l}\text { COMP-2: Using Moodle fits with my } \\
\text { teaching style }\end{array}$ & 5.17 & 1.26 & $0.89 *$ \\
\hline & $\begin{array}{l}\text { COMP-3: Moodle is compatible with most } \\
\text { aspects of my teaching }\end{array}$ & 4.66 & 1.36 & $0.82 *$ \\
\hline \multirow[t]{3}{*}{$\begin{array}{l}\text { Confirmation } \\
(\mathrm{CR}=0.91)\end{array}$} & $\begin{array}{l}\text { CON-1:My experience with using Moodle } \\
\text { was better than what I expected }\end{array}$ & 4.55 & 1.39 & $0.90^{*}$ \\
\hline & $\begin{array}{l}\text { CON-2:The benefit provided by Moodle } \\
\text { was better than what I expected }\end{array}$ & 4.59 & 1.25 & $0.90 *$ \\
\hline & $\begin{array}{l}\text { CON-3:Overall, most of my expectations } \\
\text { from using Moodle were confirmed }\end{array}$ & 4.75 & 1.14 & $0.82 *$ \\
\hline
\end{tabular}


Table 2. (Continued)

\begin{tabular}{|c|c|c|c|c|}
\hline \multirow{3}{*}{$\begin{array}{l}\text { Perceived } \\
\text { Competence } \\
(\mathrm{CR}=0.92)\end{array}$} & $\begin{array}{l}\text { PC-1: I feel very competent when I use } \\
\text { Moodle in my teaching }\end{array}$ & 4.37 & 1.50 & $0.87 *$ \\
\hline & $\begin{array}{l}\text { PC-2: Most days I feel a sense of } \\
\text { accomplishment from working with Moodle }\end{array}$ & 4.24 & 1.41 & $0.87 *$ \\
\hline & $\begin{array}{l}\text { PC-3: When I am using Moodle, I often feel } \\
\text { very capable }\end{array}$ & 4.02 & 1.48 & $0.93^{*}$ \\
\hline \multirow[t]{4}{*}{$\begin{array}{l}\text { Access } \quad(\mathrm{CR}= \\
0.87)\end{array}$} & $\begin{array}{l}\text { ACCESS-1:Moodle is responsive to my } \\
\text { request }\end{array}$ & 4.53 & 1.35 & $0.75^{*}$ \\
\hline & $\begin{array}{l}\text { ACCESS-2:Moodle quickly loads all the } \\
\text { text and graphics }\end{array}$ & 3,96 & 1.79 & $0.83^{*}$ \\
\hline & ACCESS-3:Moodle provides good access & 4.81 & 1.39 & $0.80^{*}$ \\
\hline & ACCESS-4:Moodle is stable & 4.35 & 1.45 & $0.77 *$ \\
\hline \multirow{2}{*}{$\begin{array}{l}\text { Reliability }(\mathrm{CR} \\
=0.81)\end{array}$} & REL-1:Moodle is dependable & 4.47 & 1.08 & $0.74^{*}$ \\
\hline & REL-2:Moodle operates reliably & 4.42 & 1.52 & $0.90^{*}$ \\
\hline \multirow{4}{*}{$\begin{array}{l}\text { Perceived } \\
\text { behavioral } \\
\text { control }(\mathrm{CR}= \\
0.90)\end{array}$} & $\begin{array}{l}\text { PBC-1: I am able to use Moodle well for } \\
\text { accomplishing my teaching }\end{array}$ & 5.03 & 1.42 & $0.84 *$ \\
\hline & $\begin{array}{l}\text { PBC-2: Using Moodle is entirely within my } \\
\text { control }\end{array}$ & 4.52 & 1.64 & $0.84^{*}$ \\
\hline & $\begin{array}{l}\text { PBC-3: I have the resources necessary to } \\
\text { use Moodle }\end{array}$ & 5.24 & 1.51 & $0.85^{*}$ \\
\hline & $\begin{array}{l}\text { PBC-4: I have the knowledge necessary to } \\
\text { use Moodle }\end{array}$ & 5.22 & 1.44 & $0.80^{*}$ \\
\hline \multirow{3}{*}{$\begin{array}{l}\text { Subjective } \\
\text { Norm }(\mathrm{CR}= \\
0.83)\end{array}$} & $\begin{array}{l}\text { SI-1: People important to me support my } \\
\text { use of Moodle }\end{array}$ & 4.78 & 1.48 & $0.82 *$ \\
\hline & $\begin{array}{l}\text { SI-2: People whose opinions I value prefer } \\
\text { that I use Moodle for doing my teaching }\end{array}$ & 4.53 & 1.37 & $0.85^{*}$ \\
\hline & $\begin{array}{l}\text { SI-3: In general, the school has supported } \\
\text { the use of Moodle }\end{array}$ & 4.70 & 1.40 & $0.68^{*}$ \\
\hline
\end{tabular}

$\mathrm{CR}=$ Composite reliability; ${ }^{*} \mathrm{p}<0.001$

Testing for discriminant validity involves checking whether the items measure the construct in question or other (related) constructs. Discriminant validity was verified with correlation analysis as recommended by Gefen and Straub [24]. The inspection of discriminant validity among variables is based on the correlation between variables and the square root of their respective average variance extracted [22]. As Table 3 shows, the squared root of the average variance extracted value for the variables is consistently greater than the off-diagonal correlation values, suggesting satisfactory discriminant validity among variables. 
Table 3. Correlation among variables and squared root of average variance extracted

\begin{tabular}{llllllllll}
\hline & $(\mathbf{1})$ & $\mathbf{( 2 )}$ & $\mathbf{( 3 )}$ & $\mathbf{( 4 )}$ & $\mathbf{( 5 )}$ & $\mathbf{( 6 )}$ & $\mathbf{( 7 )}$ & $\mathbf{( 8 )}$ & (9) \\
\hline ACCESS (1) & $\mathbf{0 . 7 9}$ & & & & & & & & \\
COMP (2) & 0.58 & $\mathbf{0 . 8 8}$ & & & & & & & \\
CON (3) & 0.68 & 0.63 & $\mathbf{0 . 8 7}$ & & & & & & \\
EOU (4) & 0.67 & 0.68 & 0.56 & $\mathbf{0 . 8 7}$ & & & & & \\
PBC (5) & 0.44 & 0.65 & 0.44 & 0.69 & $\mathbf{0 . 8 4}$ & & & & \\
PU (6) & 0.67 & 0.78 & 0.73 & 0.60 & 0.60 & $\mathbf{0 . 8 3}$ & & & \\
PC (7) & 0.62 & 0.65 & 0.55 & 0.74 & 0.65 & 0.64 & $\mathbf{0 . 8 9}$ & & \\
REL (8) & 0.73 & 0.41 & 0.53 & 0.54 & 0.34 & 0.48 & 0.42 & $\mathbf{0 . 8 2}$ & \\
SN (9) & 0.38 & 0.45 & 0.32 & 0.38 & 0.45 & 0.44 & 0.48 & 0.30 & $\mathbf{0 . 7 9}$ \\
\hline
\end{tabular}

Note: Compatibility (COMP), Confirmation (CON), Ease of use (EOU), Perceived behavioral control (PBC), Perceived usefulness (PU), Perceived Competency (PC), Reliability (REL), and Subjective norm (SN).

\section{$5 \quad$ Results and Discussions}

The test of the PLS regression model includes estimates of the path coefficients, which indicates the strengths of the relationships between the dependent and independent variables, and the R-square values, which represent the amount of variance explained by the independent variables. Fig. 3 shows the results of the test of the hypothesized model. Three out of our four hypotheses are supported.

As expected, confirmation of initial expectations $(\beta=0.38 ; p<0.001)$, control beliefs $(\beta=0.21 ; \mathrm{p}<0.05)$, and system characteristics $(\beta=0.30 ; \mathrm{p}<0.01)$ have a significant impact on perceived usefulness. On the other hand, and social aspect $(\beta=$ 0.07 , ns) have no significant effect on perceived usefulness. Taken as a whole these predictors explained $68 \%$ of the total variance in perceived usefulness.

The supported hypotheses are discussed below. First, as expected confirmation affects perceived usefulness significantly. This finding is in line with the previous findings [1]. Second, we found that perceived system quality strongly predicts perceived usefulness. This finding is in line with the IS adoption [2] and success studies [13]. Our findings suggest that all the system quality related factors: perceived compatibility, ease of use, reliability, and access are important in shaping perceived usefulness. While the factors: ease of use, reliability, and access are often regarded as the system quality related attributes and found to have a direct impact on perceived usefulness, the interesting finding of our study is the importance of perceived compatibility as a system quality related variable affecting perceived usefulness. Our finding implies that educators bear distinct knowledge about their teaching situations, which they use as a basis for determining what tasks can be performed with a given elearning system. If the system is compatible with what the educators do in their teaching, the educators find the system useful. Conversely, if the system provides lot of important functionalities with a user-friendly interface but does not provide the functionalities that are needed for completion of educators' teaching tasks, educators 


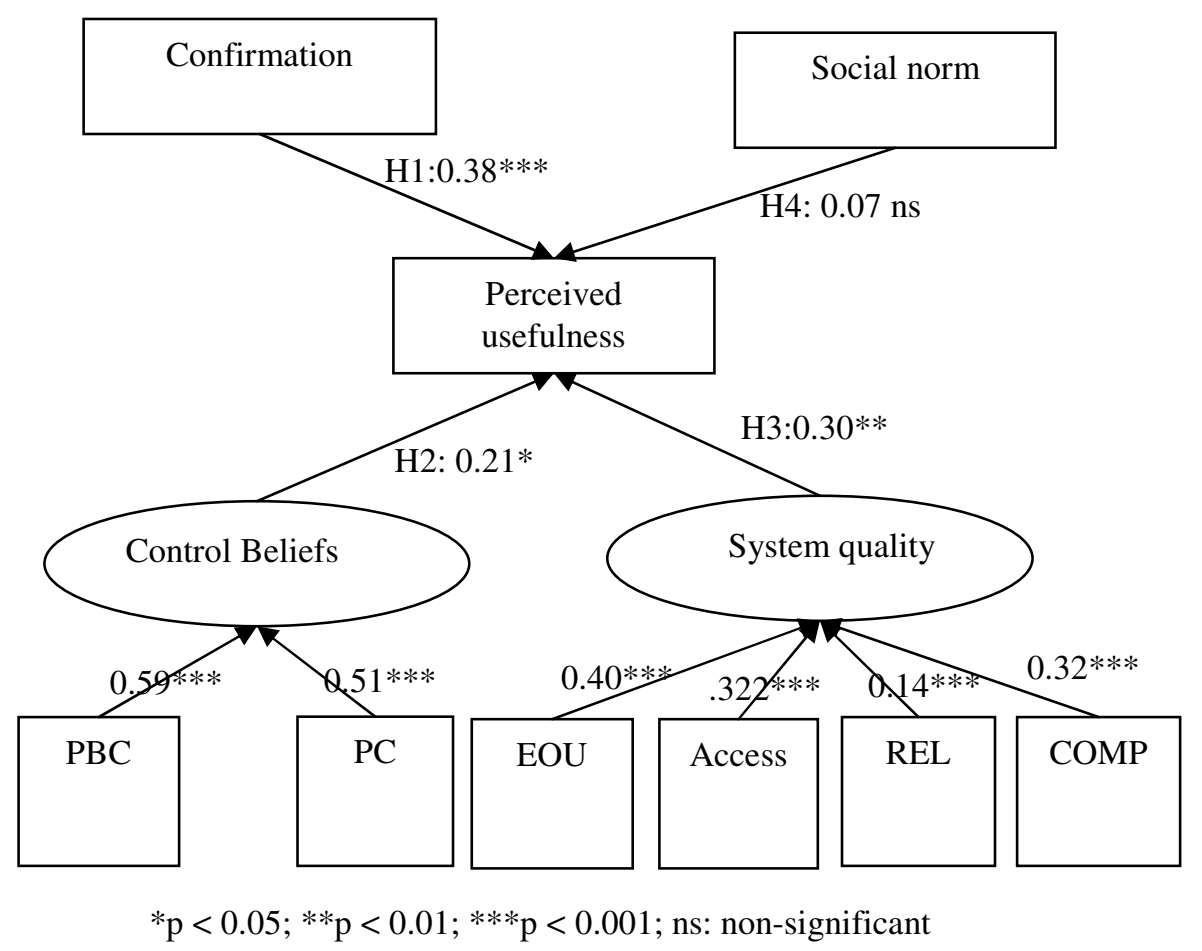

Fig. 3. Table 4. Fig. 3. PLS model results

would feel the system as not useful. Third, perceived control beliefs were also found to have a significant impact on perceived usefulness. Our study results revealed that both control beliefs: perceived behavioral control and perceived competency are significant to predict perceived usefulness. Our finding about the relationship between perceived competency and perceived usefulness implies that educators who perceive themselves competent enough in using the functionalities of a system are likely to feel the system as useful. Perceived competence is not so common in IS research, especially in IS adoption and use research. However, recently a number of studies are found that used perceived competence to extend expectation-confirmation based IS continuance model $[6 ; 8]$. These studies found a significant positive relationship between perceived competence and perceived usefulness. Thus, our finding is in line with the prior findings. Our finding about the relationship between perceived behavioral control and perceived usefulness implies that educators who perceive ease in using the system is likely to feel the system as useful.

Our study results revealed that social norm do not have a significant impact on perceived usefulness. This is in line with the findings of Hartwick and Barki [25] where they found that although subjective norm had a significant effect on intentions prior to system development, the effect became non-significant three months after system implementation. They interpreted that before a system is developed, users' 
knowledge and beliefs about a system are vague and ill-formed, and they must therefore rely more on the opinions of others as a basis for their intentions. After implementation, when more about the system's strengths and weaknesses are known through direct experience, the subjective norm's influence weakens. The educators in our study had prior experience with the target technology. Thus, their knowledge and beliefs about the system are concrete and eventually they do not evaluate others' opinion to develop their post-adoption expectations.

\section{Implications}

Our study findings have theoretical implications. First, our study adds richness to our understanding of users' post-adoption expectations. Second, our study revealed a number of general determinant factors that shape post-adoption expectations. We believe that there might be more general and context-specific factors that might influence post-adoption expectations. Thus, researchers should investigate more to underpin the most important factors that shape post-adoption expectations.

Our study findings have a number of practical implications too. First, the strong effect of perceived system quality on post-adoption expectations provides e-learning developers and managers in planning appropriate strategies to influence users' postadoption expectations. Our results imply that the management and developers should develop such a system that is compatible to educators' existing values and needs. The designers should understand the educators' teaching tasks and develop such system that is compatible to educators' teaching tasks. In addition, they should develop such systems that are easy to use, and reliable. The service providers who host the elearning services in the Internet also should put enough effort to ensure accessibility. Second, our study also revealed that confirmation has a significant strong impact on post-adoption expectations. Thus, the management should develop strategies so that the educators may build appropriate level of initial expectations. It would allow the users to positively confirm their initial expectations. Latter, it will affect the postadoption expectations. Third, we found control beliefs have also a significant impact on post-adoption expectations. This finding implies that the management should plan for actions that might improve educators' control beliefs. Specially, training could be arranged for the users and instruction manuals should be available to the users.

\section{Conclusions}

In this study, we developed a research model based on expectation-confirmation framework to underpin the factors that are salient to shape users' post-adoption expectations. In particular, we hypothesized that confirmation, perceived control beliefs, perceived system quality, and social norm would be salient for shaping postadoption expectations. Then, we collected survey data from 175 university educators who use an e-leaning platform for teaching purpose, and analyzed the data using structured equation modeling. Study's findings revealed that post-adoption expectation is mainly determined by confirmation of initial expectations, perceived 
control beliefs, and perceived system quality. Social norm was not found to have significant impact on user satisfaction. In sum, our study revealed three main antecedents of post-adoption expectations. However, as the study was conducted in the university settings, caution should be taken before generalizing the results of this study to other context. Thus, similar kinds of studies are needed to conduct in different contexts.

\section{References}

1. Bhattacherjee, A.: Understanding Information Systems Continuance: An ExpectationConfirmation Model. MIS Quarterly 25(3), 251-370 (2001)

2. Davis, F.D.: Perceived usefulness, perceived ease of use, and user acceptance of information technology. MIS Quarterly 13(3), 319-340 (1989)

3. Venkatesh, V., Bala, H.: Technology acceptance model 3 and a research agenda on interventions. Decision Sciences 39(2), 273-314 (2008)

4. Hong, S.-J., Thong, J.Y.L., Tam, K.Y.: Understanding continued information technology usage behavior: A comparison of three models in the context of mobile internet. Decision Support Systems 42(3), 1819-1834 (2006)

5. Churchill Jr., G.A., Surprenant, C.: An investigation into the determinants of customer satisfaction. Journal of Marketing Research 19(4), 491-504 (1982)

6. Roca, J.C., Gagne, M.: Understanding e-learning continuance intention in the workplace: A self-determination theory perspective. Computers in Human Behavior 24(4), 1585-1604 (2008)

7. Larsen, T.J., Sorebo, A.M., Sorebo, O.: The role of task-technology fit as users' motivation to continue information system use. Computers in Human Behavior 25, 778-784 (2009)

8. Sorebo, O., Halvari, H., Gulli, V.F., Kristiansen, R.: The role of self-determination theory in explaining teachers' motivation to continue to use e-learning technology. Computers \& Education 53, 1177-1187 (2009)

9. Liao, C., Chen, J.L., Yen, D.C.: Theory of planning behavior (TPB) and customer satisfaction in the continued use of e-services: An integrated model. Computers in Human Behavior 23(6), 2804-2822 (2007)

10. Ajzen, I.: The theory of planned behavior. Organizational Behavior and Human Decision Processes 50(2), 179-211 (1991)

11. White, R.W.: Motivation reconsidered: The concept of competence. Psychological Review 66, 297-333 (1959)

12. Deci, E.L., Ryan, R.M.: Human autonomy: The basis for true self-esteem. In: Kemis, M. (ed.) Efficacy, Agency, and Self-Esteem, pp. 31-49. Plenum, New York (1995)

13. Seddon, P.B.: A Respecification and Extension of the DeLone and McLean Model of IS Success. Information Systems Research 8(3), 240-253 (1997)

14. Lee, J.-K., Lee, W.-K.: The relationship of e-Learner's self-regulatory efficacy and perception of e-Learning environment quality. Computers in Human Behavior 24, 32-47 (2008)

15. Lee, S., Shin, B., Lee, H.G.: Understanding post-adoption usage of Mobile Data Services: The role of supplier-side variables. Journal of the Associations for Information Systems 10(12), 860-888 (2009)

16. Moore, G.C., Benbasat, I.: Development of an instrument to measure the perception of adopting an Information Technology innovation. Information Systems Research 2(3), 192$222(1991)$ 
17. Wixom, B.H., Todd, P.A.: A Theoretical Integration of User Satisfaction and Technology Acceptance. Information Systems Research 16(1), 85-102 (2005)

18. Fishbein, M., Ajzen, I.: Belief, Attitude, Intention, and Behavior: An introduction to the Theory and Research. Addison-Wesley, Reading (1975)

19. Venkatesh, V., Davis, F.D.: A theoretical extension of the technology acceptance model: Four longitudinal field studies. Management Science 46(2), 186-204 (2000)

20. Venkatesh, V., Morris, M.G., Davis, G.B., Davis, F.D.: User acceptance of information technology: toward a unified view. MIS Quarterly 27(3), 425-478 (2003)

21. Ringle, C.M., Wende, S., Will, A.: Smart PLS 2.0 M3. University of Hamburg (2005), http: / / www. smartpls.de

22. Fornell, C., Larcker, D.F.: Evaluating structural equation models with unobservable variables and measurement error. Journal of Marketing Research 18(1), 39-50 (1981)

23. Nunnally, J.C.: Psychometric theory, 2nd edn. McGraw Hill, New York (1978)

24. Gefen, D., Straub, D.: A practical guide to factorial validity using PLS-Graph: Tutorial and annotated example. The Communications of the Associations for Information Systems 16(5), 91-109 (2005)

25. Hartwick, J., Barki, H.: Explaining the role of user participation in information system use. Management Science 40, 440-465 (1994) 